\title{
NOTE ON THE BAG WORM, THYRIDOPTERIX.
}

BY J. ARTHUR HARRIS, COLD SPRING HARBOR, N. Y.

IN an interesting memoir on the constriction of twigs by the Bag Worm, Dr. von Schrenk ${ }^{1}$ has presented certain data which seem to me to deserve consideration from a somewhat different point of view.

Dr. von Schrenk found that the insect attaches the bags almost without fail only to one-year-old twigs. Whether this is done because these are the twigs upon which the insect has been feeding, or whether because of their size he was unable to determine. But he did find, by an interesting experiment, that they would not form bands around very large twigs, but glued them to one side instead, although they always formed the band entirely around smaller twigs.

On page 176 Dr. von Schrenk remarks: "The first analysis of the measurements made deals with the size of the bands in their relation to the size of the twigs to which they were attached.... On Table I the bands taken from maple twigs are arranged according to their width and according to the diameter of the twigs. It will be noted that the largest number of bands occurred on twigs $3 \mathrm{~mm}$. in diameter, and that there is a regular falling off towards both sides; in other words, the insect seems to select twigs having a diameter of about $3 \mathrm{~mm}$."

Now I think there are two points which may be given especial consideration from this table. These are the questions:-

a) Is there any selection of twigs according to size?

b) Is there any relationship between the size of the twig and the width of the band formed by the insect?

It is question a) which Dr. von Schrenk has in mind when he writes of "the size of the bands in their relation to the size of the twigs," I think. Possibly he had the second problem in view as well, but he does not draw especial attention to it.

Now as to question a) it seems to me that unfamiliarity with biometric methods has led Dr. von Schrenk into a slip in his consideration of this point. So far as I can see his data do not enable us to determine whether there has been a selection of twigs at all. It is well known that measurements made upon practically any plant organ vary around a modal condition, roughly speaking in accordance with some mathe-

1 von Schrenk, H. Constriction of Twigs by the Bag Worm and Incident Evidences of Growth Pressure. Ann. Rept. Mo. Bot. Gard. 17, 155-181. 1906. 
matical law of distribution. To find more bands on one sort of a twig than on another does not necessarily show that there has been any selection of twigs; it may indicate merely that there were more of that particular class of twigs available. To determine whether there has been any selection of twigs we must, in short, have measurements of series of twigs upon which the insects do not form bags as well as those upon which they do. The question which Dr. von Schrenk raises is one of very considerable biological interest, but for a trustworthy answer we should compare the means and variabilities of twigs bearing the bags with the same constants of those which do not. Naturally enough it would be necessary to confine attention to the one-year-old twigs in making the comparison. Perhaps the lengths of the twigs should be taken into consideration also, for other things being equal a larva would be more likely to form a bag upon a long twig than upon a short one. Actual data suitable to decide this interesting question should be collected by some one.

The second question seems to me to be of considerable interest as well. If the larvae refuse to form bands around large twigs, it seems quite natural to ask whether they modify the size of the bands according to the size of the twig to which they are attached. Even if the insect does not "purposely" make any modification in the size of the band, is it possible that the amount of material available has any influence upon the width of the bands formed upon relatively large or small twigs?

This question can be answered preliminarily by a proper statistical analysis of the data in the table given. The relationship between the size of the twigs and the width of the bands is satisfactorily shown by the coefficient of correlation. ${ }^{1}$ This constant may range from 0 to plus or minus 1 . A coefficient of 1 denotes perfect relationship while a coefficient of 0 shows that there is no relationship between the magnitudes of two characters under consideration. Every statistical constant has a probable error which gives some indication of the significance which is to be attached to it. To be considered significant the coefficient of correlation should be at least two and one half times its probable error.

Calculating the correlation from the table given, ${ }^{2}$ and using Sheppard's corrections for the second moment in calculating the standard deviations, I find that the interdependence of band width and twig diameter is represented by 0.016 with a

\footnotetext{
1 For a discussion of the method of calculating the coefficient of correlation, see any of the text, books on biometric methods, as Davenport's Statistical Methods, Elderton's Frequency Curves and Correlation, or Thorndyke's Introduction to the Theory of Mental and Social Measurements.

2 The fewness of the bands recorded as $2.5 \mathrm{~mm}$. in width as compared with those 2 and $3 \mathrm{~mm}$. in width at once arouses the statistician's suspicions that the result is not a biological condition but a result of the tendency of observers to read to whole numbers instead of fractions. In future work this point should be carefully watched.
} 
probable error of 0.033 . The correlation is only about half its probable error and consequently no significance at all can be attached to it. Clearly, therefore, there is no modification of the width of the band dependent upon the size of the twig upon which it is formed.

Of course this conclusion applies only to the present series of data; further measurements might yield different results. Dr. von Schrenk's series of measurements somewhat exceeds 400 , however, and this may be regarded as a fairly satisfactory number for the solution of the second of the two problems. The first still remains for solution and collections of data towards this end ought to be made.

\section{COLEOPTERA TAKEN AT FRAMINGHAM, MASS.}

\section{A. Frost.}

THE following species of Coleoptera have been taken during the past four seasons in this locality and some of them at least have never been recorded from New England.

Cicindela purpurea, var. audubonii, Lec. One ㅇ specimen, Sept. 4, 1904. This has been recorded once before in Psyche, but it has recently been critically examined and compared with western audubonii by Mr. Edw. D. Harris who considers its capture in Mass. remarkable.

Elaphrus cicatricosus, Lec. One specimen, May 10, 1907, taken near a small brook when this was flooded by water from a cranberry bog. (One specmen of this species was taken at Monmouth, Maine, on lake shore during June, 1906.)

Elaphrus clairvillei, Kirby. Four specimens taken in the muddy bed of a dried up brook, Sept. 6, 1907.

Lachnocrepis parallelus, Say, and Anatrichis minuta, Dej. Mr. Frederick Blanchard, who identified them, writes me that he has one specimen of the former from Lowell, Mass., and a single specimen of the latter from Florida.

Acilius fraternus, Harr. Four specimens; Acilius semisulcatus, Aube being the common species here. One specimen of A. mediatus, Say has been taken, Aug. 25, 1907.

Limonius stigma, Hbst. Two specimens, June 8, 1907, and May 27, 1908. Agrilus blanchardi, Horn. One specimen, July 27, 1907. Probably this species is mixed with $A$. anxius, Gory in collections. 

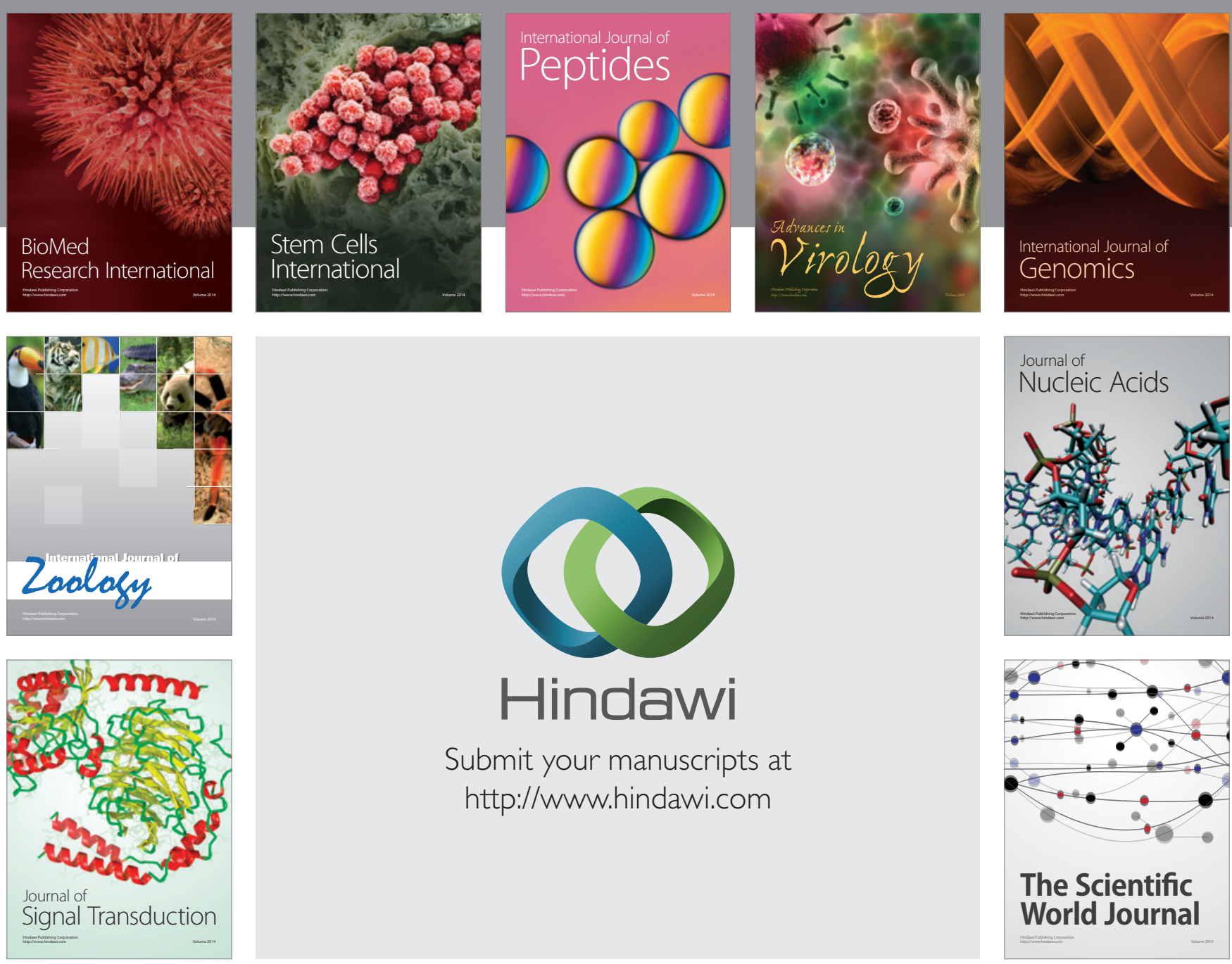

Submit your manuscripts at

http://www.hindawi.com
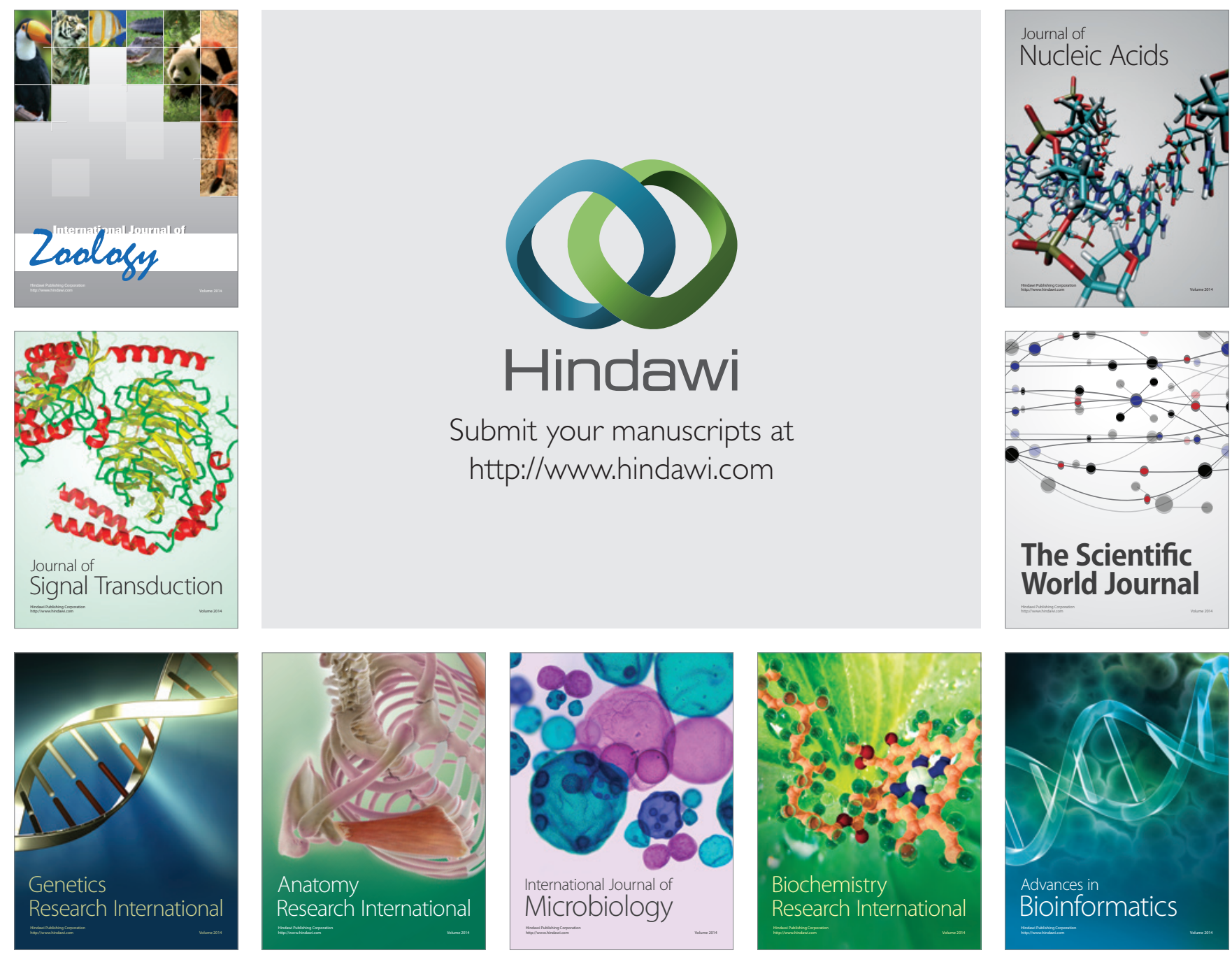

The Scientific World Journal
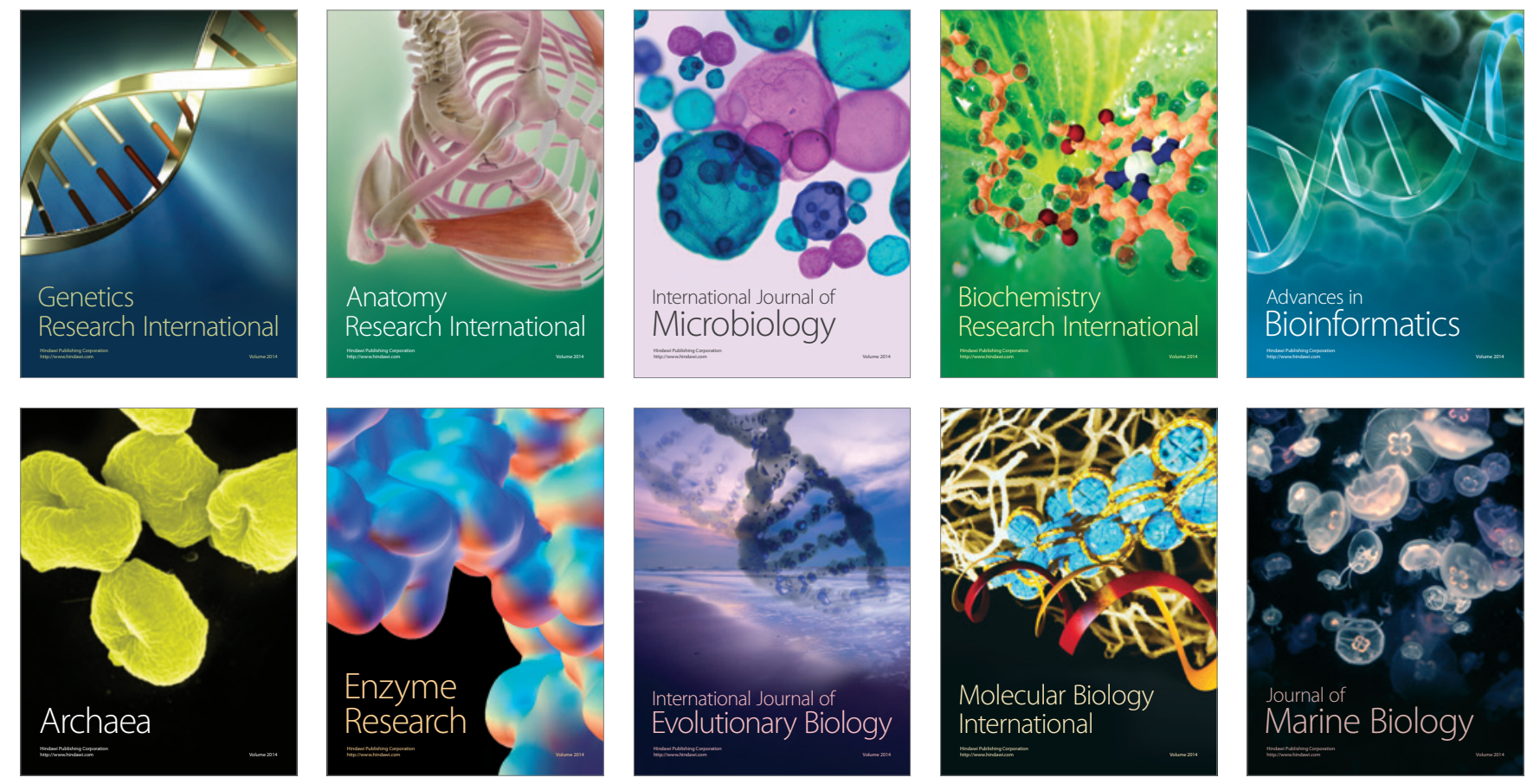